\title{
Propositions and Properties*
}

ADAM PAUTZ

Brown University

Consider claims of the following kind:

[1] The proposition that the ball is white represents that the ball is white.

[2] The proposition that the ball is white and the ball is round represents that the ball is white and the ball is round.

In his excellent book Propositions, Trenton Merricks supports with great force and rigor a theory of propositions. His main theses are: (I) Propositions are abstract objects that exist necessarily. (II) They are simple, lacking proper parts and settheoretic constituents. The proposition that the ball is white doesn't have as constituents the ball or the property being white. And even the so-called "complex" proposition that the ball is white and the ball is round doesn't have as constituents the proposition that the ball is white and the proposition that the ball is round. (III) Finally, all truths like [1] and [2] lack explanation. Call this No Explanation. In defending No Explanation Merricks opposes recent work that starts from the intuition that such truths must have an explanation.

I will make three points. First, I will suggest that Merrick's No Explanation thesis receives additional support from parallels between propositions and properties. Second, Merricks offers no analysis of representational truths about propositions like [1] and [2]. But I will suggest that No Explanation is compatible with, and indeed fits well with, the idea that such truths do indeed have a kind of analysis, one drawing on the notion of constitutive essence. Third, I will conclude by raising a problem about how we manage to bear attitudes to propositions.

\section{Propositions and Properties: Some Parallels}

At the end of Propositions, Merricks addresses an objection to No Explanation (207-214). The objection is that truths about propositions like [1] and [2] intui-

\footnotetext{
* For comments on an earlier draft, I thank Brian Cutter, Jeremy Goodman, Jon Litland, Bryan Pickel, and Jeff Speaks. I am also indebted members of my 2010 metaphysics seminar at the University of Texas at Austin where I discussed the proposition-property parallels touched on here in $\S \S 1-2$. Ostertag (2013) briefly reports that Robert Stalnaker has also stressed such a parallel (thanks to Ray Buchanan for this reference).
} 
tively "cry out for explanation". ${ }^{1}$ In fact, this point is the starting point for recent work on propositions by Scott Soames and Jeff King, among others. As Merricks notes (207), they develop rival views according to which such truths can somehow be explained by our cognitive activity.

Merricks offers helpful responses to the Explanatory Objection. I think he might have included yet another response, one drawing on parallels between propositions and properties.

To begin with, those who accept [1] and [2] believe in atomic and "complex" propositions. And those who believe in atomic and "complex" propositions are also likely to believe in basic and "complex" properties. And they are likely to accept claims about properties like these:

[3] For any $x, x$ instantiates the property being white (an abstract object) on the condition that $x$ is white.

[4] For any $x, x$ instantiates the property being white and round on the condition that $x$ instantiates being white and $x$ instantiates being round (and therefore on the condition that $x$ is white and $x$ is round).

Now, just as some have said that truths about propositions like [1] and [2] demand explanation, others have said that truths about properties like [3] and [4] demand explanation (Lewis 1986a, 190, fn.13; 1986b, 41-42). In fact, there are striking parallels between the two issues.

I think it can be argued that explanations of truths about properties like [3] and [4] fail.

As noted, opponents of Merricks like King and Soames try to somehow explain truths about propositions like [1] and [2] on the basis of our cognitive activity. But our cognitive activity certainly cannot explain truths about properties like [3] and [4]!

Those bent on explanation might concede that the instantiation-conditions of "basic" properties cannot be explained but insist that the instantiation-conditions of "complex" properties can be explained in terms of their "constituents" and "structure". So, for instance, maybe [3] cannot be explained, if we pretend that being white is a "basic" property - it is just part of the essence of this property to be instantiated by things when they are white. But maybe [4] can be explained by the allegedly more basic fact that the property being white and round has the properties being white and being round "as constituents", where that means "parts" or "members".

\footnotetext{
${ }^{1}$ A different objection to Merricks's view is that it's intrinsically implausible that one abstract simple necessarily represents that the ball is white (and its being "true" up there in Plato's heaven necessitates that the ball is white down here in the concrete realm), another abstract simple necessarily represents that Napoleon used a stand up desk (and its being "true" necessitates that Napoleon used a stand up desk), and so on.
} 
This constituent-based explanation of the instantiation-conditions of complex properties is very similar to constituent-based explanations of the truth-conditions of propositions. Merricks develops a number of criticisms in the case of both "atomic" and "complex" propositions (chapter 4; chapter 6, sect. II). For one thing, if the propositions $A$ loves $B$ and $B$ loves $A$ have the same "constituents" but different truth-conditions, then simply citing their "constituents" isn't enough to explain their truth-conditions. The constituent-based explanation likewise fails for properties. For instance, if being white and round and being white or round have the same constituents but different instantiation-conditions, then citing their constituents isn't enough to explain their instantiation-conditions. Other examples illustrate the same point, for instance being butane and being isobutane (Lewis 1986b, 36-38).

For both basic and "complex" properties, there is arguably no answer to the question: what is the account of properties which explains why they paired with the specific instantiation-conditions they are paired with? It's just in their nature. "No Explanation" is pretty clearly right for properties.

This provides Merricks with a new response to the Explanatory Objection to his view. For truths about atomic and "complex" propositions like [1] and [2] are at least $a$ bit similar to truths about basic and complex properties like [3] and [4]. They all concern "the conditions on the world" that must obtain in order for certain abstract objects to be "satisfied". ${ }^{2}$ So, once you admit that countless truths about properties like [3] and [4] cannot be explained, you should somewhat lower your credence that similar truths about propositions like [1] and [2] must be explained (it's just a "drop in the bucket" to hold that they also lack explanation). That is, you should lower your credence in the Explanatory Objection to Merricks's No Explanation view. Indeed, by considerations of uniformity, you should increase at least somewhat your credence in that thesis. Call this the parallel point.

Now advocates of the Explanatory Objection to Merricks's view won't be happy with my parallel point. They will say that there is a big difference. Propositions represent (as do sentences, stories, perceptions, and so on), and they have truth-conditions. Properties don't represent - they just have instantiationconditions. And advocates of the Explanatory Objection will say they somehow have a priori reason to think that such "representational" truths about propositions have an explanation (perhaps one involving agents) but the instantiation-conditions of properties don't.

But Merricks could say a few things here. First, yes, in some sense, the proposition that the ball is white "represents" that the ball is white. But this way of putting it may exaggerate the difference between the relevant facts about propositions and properties. In philosopher-speak, another way of saying that this proposition "represents" that the ball is white is by saying that its truth-condition is that the

\footnotetext{
${ }^{2}$ Some claim that propositions and properties belong to the same "ontological category" and that propositions are just "zero-place properties". But the point I'm developing only requires the weaker claim that truths like [1] and [2] are at least somewhat similar to truths like [3] and [4].
} 
ball is white. ${ }^{3}$ And this does look similar to the fact that the property being white has as its instantiation-condition that a thing be white. Second, yes, opponents of Merricks might insist that they somehow have a priori reason to think truths about propositions like [1] and [2] must have an explanation but truths about properties like [3] and [4] may lack one. (Maybe because they have a special, discriminating intuition that the rest of us don't share.) But many of us don't find this at all. Just look at [3] and [4] and then look at [1] and [2]. Is it really pre-theoretically clear that there is a big difference in the degree to which these truths "cry out for explanation" - in terms of agents or anything else? Finally, suppose that opponents of Merricks still answer "yes": for them at least, there is some a priori reason to expect that [1] and [2] have an explanation, while this is not true of [3] and [4]. This doesn't affect the parallel point. For this alleged a priori expectation is defeasible. And since there is at least some similarity between these truths, and since [3] and [4] have no explanation, it's undeniable that the parallel point provides some defeat.

\section{Can Notion of a Proposition's "Representing" be Analyzed?}

Consider [1] again:

[1] The proposition that the ball is white represents that the ball is white.

As I said, Merricks favors No Explanation: [1] lacks explanation (e. g. in terms of the "structure" of the proposition, or our cognitive activity). But I want to suggest that this is compatible with a certain kind of analysis of [1].

As a way of leading up to my proposal, let's first consider a simple Modal Analysis of [1]. On this analysis, "proposition $x$ represents that $\mathrm{p}$ " is analyzable as "necessarily, proposition $x$ is true iff p". So [1] is equivalent to

$[\mathrm{N}]$ Necessarily, the proposition that the ball is white is true iff the ball is white

This Modal Analysis fails because "proposition $p$ represents that " is hyperintensional while "necessarily, proposition $p$ is true iff ___" is not. So, for instance, necessarily, the proposition that the ball is white is true if and only if the ball is white and all dogs are dogs. But, contrary to the Modal Analysis, it doesn't represent that the ball is white and all dogs are dogs.

Now the alternative analysis I want to suggest has the same form as the Modal Analysis but appeals to essence instead of necessity. Kit Fine (1995) has argued for the importance in metaphysics of the hyperintensional, pre-modal notion "It is in

\footnotetext{
${ }^{3}$ Two clarifications: First, here we're using the notion of "the truth-condition" in a hyperintensional sense: so, for instance, it's not right to say that this proposition has the truthcondition the ball is white and all dogs are dogs. Second, I don't mean to be "reifying" truth-conditions.
} 
the constitutive (non-derivative) essence of $x$ that __. Armed with this notion, we might analyze "proposition $x$ represents that p" as "it is in the constitutive essence of proposition $x$ that it is true iff p". So [1] amounts to:

[E] It is in the constitutive essence of the proposition that the ball is white that it is true if, and only if the ball is white. ${ }^{4}$

This Essentialist Analysis avoids the hyperintensionality problem facing the Modal Analysis. True, necessarily, the proposition that the ball is white is true if and only if the ball is white and all dogs are dogs. But this isn't something that is true just by virtue of the constitutive essence of that proposition. What is true by virtue of the constitutive essence of the proposition - a simple abstract object - is just that it is true iff the ball is white. So that is what it represents, according to this analysis. The same analysis applies to [2].

The Essentialist Analysis extends naturally parallel claims about properties like [3] and [4]. It's just part of the constitutive essence of being white that it is instantiated by white things, and it's just part of the constitutive essence of being white and round that it's instantiated by white and round things. Here's another example. Necessarily, the property being round and square is instantiated by something iff that thing is triangular and oval. But that's not its instantiationcondition. On the Essentialist Analysis, what is true by virtue of the constitutive essence of the property being round and square is just that it is instantiated by something iff that thing has the property being round and it has the property being square. So that's its instantiation-condition. Such "complex" properties don't literally have "constituents". Rather, the full account of their essences must mention other properties.

The Essentialist Analysis fits well with some things Merricks says and has several virtues.

[I] On the Essentialist Analysis, the representational property representing the ball as white is "analyzable" in terms of essence and truth. That is, it is identical with the essentialist property being essentially such as to be true iff the ball is white. This entails a form of Merrick's No Explanation thesis. It entails that, whenever a proposition has the representational property, this is not grounded in its having any other property. For it is identical with the essentialist property; and in general a thing's having such an essentialist property is not grounded in anything else.

[II] Merricks (p.20) holds that the representational fact [1] explains the truthconditional fact $[\mathrm{N}]$. On the Essentialist Analysis, this because [1] is equivalent to $[\mathrm{E}]$ and $[\mathrm{E}]$ explains $[\mathrm{N}]$. In general, essentialist truths explain necessary truths.

Relatedly, Merricks accepts particular representation-truth explanations. For instance, the representational fact [1] can be combined with "the ball is white" to explain why the proposition that the ball is white is true. On the Essentialist Anal-

\footnotetext{
${ }^{4}$ Brian Cutter suggested a slight addition to my analysis [E]: It is in the constitutive essence of the proposition that the ball is white that it is true iff, and because, the ball is white. However, I will work with [E] for simplicity.
} 
ysis, this is because [1] is equivalent to [E], and [E] can be combined with "the ball is white" to explain this. ${ }^{5}$

[III] As noted above, the Essentialist Analysis explains the hyperintensionality of "proposition $p$ represents that _ " and the hyperintensionality of "property $P$ has as its instantiation condition that __. These aren't brute facts; they flow from the hyperintensionality of "It is in the constitutive essence of $x$ that __".

[IV] Intuitively, essentialist claims like [E] are true. The simplest view is therefore that representational facts like [1] just are these essentialist facts.

[V] The Essentialist Analysis applies uniformly to propositions and properties.

Despite these virtues, I think Merricks would reject the Essentialist Analysis of representational facts like [1] and [2], for two reasons. First, he not only accepts No Explanation. He also gives no analysis of such facts. ${ }^{6}$ So for him the representational properties of propositions (e. g. representing that the ball is white) are not only ungrounded in anything more basic (No Explanation); they are also fundamental, unanalyzable properties of propositions (and so not analyzable in terms of essence and truth), which explain their truth-conditions. Call this No Analysis. Second, above I said that the Essentialist Analysis is compatible with particular representation-truth explanations ([II]). But it is incompatible with another claim Merricks makes. He claims that "the predicate 'is true' applies to a proposition just in case that proposition represent things as being a certain way and things are as that proposition represents them as being" (p.20, fn.10). His apparent claim here that truth is analyzable in terms of representation is incompatible with claim of Essentialist Analysis that representation is analyzable in terms of truth and essence. ${ }^{?}$

So Merricks apparently accepts the No Analysis view of propositional representation. But I have shown that the Essentialist Analysis is also compatible with his No Explanation thesis. I think Merricks might consider rejecting No Analysis in favor of the Essentialist Analysis, because I'm not sure he can show that No Analysis shares all the virtues of the Essentialist Analysis (especially [III]-[V]).

To take just one example: the Essentialist Analysis has the virtue [V] of applying naturally and uniformly to propositions and properties. Intuitively, propositions

\footnotetext{
${ }^{5}$ Merricks also holds (186-187) that [1] and [N] don't entail "there is an $x$ such that $x=$ the ball". The Essentialist Analysis can accommodate this too if we say that [E] likewise doesn't have this entailment.

${ }^{6}$ Merricks claims (21) that the proposition that the ball is white essentially represents that the ball is white, but I hope it is obvious that this doesn't mean he holds that propositional representation is itself analyzable in terms of essence and truth as I've suggested.

${ }^{7}$ Merricks doesn't say how to formulate such an analysis in a way consistent with his view (189) that the representational properties of propositions aren't relations to any kind of items. One idea would be to offer a disjunctive or "big list" analysis: proposition $p$ is true = proposition $p$ has the fundamental non-relational property representing that the ball is white and the ball is white or proposition $p$ has the fundamental non-relational property representing that Napoleon used a standup desk and Napoleon used a standup desk or . . . Another idea is to invoke a primitive and ontologically non-committal higher-order quantifier that allows for quantification into sentence position: proposition $p$ is true $=$ for some $\mathrm{s}$, proposition $p$ has the property representing $\mathrm{s}$ and $\mathrm{s}$.
} 
do have nonfundamental essentialist properties like: being essentially such as to be true iff $p$. Intuitively, properties have similar nonfundamental essentialist properties: being essentially such as to be instantiated by something iff it is $F$. They're nonfundamental in that they're analyzable terms of essence, truth, and instantiation. By contrast, Merricks's rival No Analysis view doesn't apply so naturally and uniformly to the two cases. For, on the No Analysis view, propositions have distinct fundamental representational properties (like "representing the ball as white") that are prior to, and explain, their truth-conditions (e. g. [1] is unanalyzable but explains $[\mathrm{N}])$. So the parallel view in the case of properties would be that they likewise have distinct fundamental (higher-order) properties that are prior to, and explain, their instantiation-conditions. ${ }^{8}$ Such alleged fundamental properties would be distinct from the aforementioned essentialist properties. But here this view is very unnatural. (It's even hard to come up with names of the alleged extra fundamental properties of properties. Maybe "encoding that a thing is white"?) If properties don't have such fundamental higher-order properties that explain their instantiation-conditions, and there is reason to expect a uniform view, then there is some reason to doubt that propositions have such fundamental properties that explain their truth-conditions.

\section{How Do We Bear attitudes to Propositions?}

On Merricks's view, as I view a tomato, I bear the believing relation to the proposition that the tomato is round, a simple abstract object. And I bear this relation to countless other propositions. For instance, I bear this relation to the proposition that two plus two is four, rather than the proposition that two quus two is four (where the quus function is some specific function that yields the same results as the plus function for accessible numbers but different results for certain inaccessible numbers). How is this?

Merricks doesn't address this issue. However, I think he is under some pressure to accept two claims.

First, Grounding Connections. There are countless necessities of the following form:

[G] Necessarily, if the non-doxastic facts about a subject are soand-so, then those facts ground the fact that the subject bears the believing relation to proposition $p$.

Further, in the actual world at least, whenever a subject believes a proposition, this is grounded in some such non-doxastic facts. In short, the doxastic facts are grounded in non-doxastic facts and cannot float free from them. Analogy: the nor-

\footnotetext{
${ }^{8}$ As I said, Merricks favors a general analysis of "proposition $x$ is true" (see my previous footnote). Uniformity would require a parallel analysis of "property $X$ is instantiated by $y$ ". Perhaps: property $X$ is instantiated by $y=$ property $X$ has fundamental property $P 1$ ("encoding that a thing is white") and $y$ is white or property $X$ has fundamental property $P 2$ ("encoding that a thing is round") and $y$ is round or...
} 
mative facts are grounded in the non-normative facts and cannot float free from them.

To illustrate, consider the total non-doxastic facts about me while viewing the tomato. They include the first-person fact that the tomato looks clearly round to me, the fact that the sentence "Hm, that tomato sure is round" runs though my inner voice, the fact that all my behavioral dispositions are appropriate to the presence of a round thing, and much else. Is there a "possible world" where all these phenomenal-functional facts are the same, and yet I "really" bear the believing relation to the proposition that the tomato is triangular, rather than the proposition that the tomato is round? This would have to be a super secret belief: not only would it not show up in my overt behavioral dispositions, it wouldn't even show up in my inner experiential life (e. g. my "inner speech", imagery, etc.)! This seems impossible. Indeed, a full description of the non-doxastic phenomenalfunctional facts about me ground the fact that I believe that the tomato is round.

Note that Grounding Connections only says that doxastic facts are grounded in non-doxastic facts. The non-doxastic facts include first-person experiential facts and experiences are arguably themselves essentially representational. So Grounding Connections certainly doesn't require the claim (criticized by Merricks at 207ff) that all representational facts are grounded in purely non-representational facts.

Now for the second claim Merricks is under pressure to accept: No Analysis. That is, there is no true identification of the form

$$
\text { [A] } \lambda x \lambda y(\text { subject } x \text { believes abstract proposition } y)=\lambda x \lambda y(x \ldots y)
$$

where the relation named on the right-side is definable in belief-independent (e. g. experiential-functional-causal) terms. ${ }^{9}$ In this sense, the believing relation is a primitive relation. Those who hold that in having beliefs we can be related to all manner of acausal abstract objects are under especially strong pressure to accept this. Just try to even gesture at a toy completion of [A] that explains, for instance, how we believe propositions about the plus function and not some quus-like function. ${ }^{10}$

Let the Primitive Grounding View be the conjunction of Grounding Connections and No Analysis. On this view, then, the believing relation is "primitive", in the sense of No Analysis. Nevertheless, there are countless grounding connections of the following form:

\footnotetext{
${ }^{9}$ For simplicity, I will treat believing as a dyadic relation (but see Merricks p.44, fn.5).

${ }^{10}$ Merricks might think that believing the proposition that $p$ is just being disposed to occurrently judge that $p$. I think that this analysis over-intellectualizes belief and that the idea of "occurrently judging" is obscure (especially for non-linguistic subjects). But even if this kind of analysis is right, it doesn't matter. For then the points I make about the believing relation - Grounding Connections and No Analysis - apply to the judging relation.
} 
[G*] Necessarily, if the non-doxastic facts about a subject are soand-so, then those facts ground the fact that the subject bears the primitive belief relation to proposition $p$.

Analogy: followers of G. E. Moore hold that goodness is primitive but that its instantiation is always grounded in the instantiation of "natural" properties.

So Merricks is under some pressure to accept the Primitive Grounding View of belief. But it has three drawbacks.

(1) Complexity. On the Primitive Grounding View, there are countless specific "grounding laws" of form [G*]. Maybe some can be derived from more general, systematic "grounding laws". But this is not obvious. In any case, the view will end up with a swarm of brute "grounding laws" of the $\mathrm{G}^{*}$-variety, which cannot be derived from more basic truths (even if they're knowable a priori). Intuitively, they add to the complexity of our theory of the world (just as brute psychophysical laws add to the complexity of dualism about experience). In this way, they differ from analyses or identifications like [A], which intuitively have the virtue of $d e$ creasing the complexity of our theory.

Merricks might respond that we must already accept such complexity elsewhere. For instance, whenever some particles together instantiate being arranged mountain-wise, then this is grounded their having certain fundamental physical and topic-neutral properties, but there is no general analysis of being arranged mountain-wise which explains all such grounding connections.

However, while I doubt that under Merricks's view the believing relation admits of metaphysical analysis, I think it's more likely that being arranged mountain does (here we can at least begin to specify toy analyses). Further, because of my next two points, I think that the Primitive Grounding View is more odd for believing than for being arranged mountain-wise.

(2) Anomalous. In general, grounding obeys a congruence constraint: if a fact involves a certain real item, then the facts which ground that fact also involve that item. For instance, I bear the friendship relation to Anna, and this is grounded in my bearing certain (emotional, behavioral, etc.) relations to Anna. Likewise, if a physical object bears the mass-in-grams relation to the number seven, this is because it bears to the number seven the relation of being mapped into it by the unique structure-preserving mapping that accords with the convention that determines the standard gram. But given the Primitive Grounding View of belief, there are countless exceptions - which is anomalous. For the fact that a person stands in the believing relation to a proposition is presumably grounded in largely concrete facts about the person that are specifiable without mentioning that proposition at all: for instance, facts about her behavioral dispositions and experiences. ${ }^{11}$

\footnotetext{
${ }^{11}$ You might think the people in the room number two because John and Jane are in the room and no one else is. This would violate congruence because the grounding fact just involves John and Jane, and not the number two. But another view (suggested to me by Kit Fine) is that the true grounding fact here is instead that there is a one-one correspondence between the numbers less than 2 (viz. 0 and 1) and the people in the room, which does involve the number two. Even if there are some more plausible violations of congruence (a
} 
(3) Arbitrary. Consider this grounding connection: certain non-doxastic facts about me (including facts about my dispositions to use arithmetical vocabulary) ground the fact that I bear the believing relation to the proposition that two plus two is four, rather than the proposition that two quus two is four.

Absent some explanation, this grounding connection looks arbitrary. But it's hard to see how Merricks might explain it. If there is an explanation, it must have two parts. First, the non-doxastic facts ground the fact that I bear non-doxastic relation $R$ to the plus proposition, and bearing $R$ to a proposition is in turn sufficient for believing it. Second, the non-doxastic facts also ground the fact that I don't bear non-doxastic relation $R^{*}$ to the quus proposition, and bearing $R^{*}$ to a proposition is necessary for believing it. The trouble is that it is very hard to see what $R$ and $R^{*}$ might be.

A final remark. Merricks might respond that the problem of intentionality is a problem for anyone who is not a Quinean eliminativist about intentionality. It's even a problem for nominalists who, unlike Merricks, don't believe in propositions (or properties, mathematical objects, functions, etc.), since they still hold that our beliefs are somehow about specific concrete things and are true or false depending on how those things are. But I've suggested that the problem is worse for those like Merricks who believe in propositions (and all those other acausal abstracta) than it is for those with more austere ontologies, because they are under especially strong pressure to accept the Primitive Grounding View of $x$ believes proposition $y$ (and $x$ is thinking about existing item $y$, etc.). And I have raised some unique problems for this view.

\section{References}

Fine, K. 1995. Ontological Dependence. Proceedings of the Aristotelian Society $\mathrm{XCV}$.

Lewis, D. 1986a. On the Plurality of Worlds. Blackwell.

Lewis, D. 1986b. Against Structural Universals. Australasian Journal of Philosophy 64.

Ostertag, G. 2013. Two aspects of propositional unity. Canadian Journal of Philosophy 43.

possibility I'm open to), my problem in the text still applies: for almost always, grounding obeys congruence, and Merricks's view apparently requires a novel and unusual exception. 